\title{
Developmental modulation of protein binding to $\beta$-globin gene regulatory sites within chicken erythrocyte nuclei
}

\author{
P. David Jackson, Todd Evans, Joanne M. Nickol, and Gary Felsenfeld \\ Laboratory of Molecular Biology, National Institute of Diabetes and Digestive and Kidney Diseases, Bethesda, Maryland \\ 20892 USA
}

\begin{abstract}
We describe the interaction of two adjacent binding sites in the chicken $\beta$-globin gene promoter with regulatory factors present in erythroid cells. One of these sites is a palindromic sequence (Pal) that binds a member of the nuclear factor 1 family; the other is the CACCC sequence found in most adult $\beta$-globin promoters. Transfection of primary erythrocytes with plasmids carrying the gene coupled to truncated promoters reveals that the Pal site inhibits and the CACCC site stimulates expression. Nuclease protection experiments on intact nuclei show that at early stages of embryonic development, the CACCC site is occupied and the Pal site is vacant, but as development progresses, the Pal site is filled gradually and the CACCC site loses its bound protein. Beyond day 15 of development, Pal is completely occupied and CACCC is empty in vivo. Parallel DNase I footprinting and gel retardation studies in vitro show that nuclear extracts contain sharply increasing Pal-binding activity as development proceeds, but CACCC-binding activity falls off only slightly. We show that the two factors bind to their sites in vitro in an anticooperative manner and conclude that this could account for the observed changes in site occupancy in vivo. Our results suggest that the Pal factor may play a role in the shutdown of adult $\beta$ globin expression late in erythroid development.
\end{abstract}

[Key Words: $\beta$-Globin; erythrocyte; Pal site]

Received August 9, 1989; revised version accepted September 15, 1989.

For many years the family of globin genes has been analyzed as a model system for the study of developmental regulation of eukaryotic gene expression (Bruns and Ingram 1973; Collins and Weissman 1984). Only recently has it become possible to explore how the entire globin family, as well as individual members, are switched on and off during development. We have been asking such questions about the control of the $\alpha$ - and $\beta$-globin genes of chicken, exploiting the capacity to isolate and transfect primary erythrocytes at any developmental stage (Hesse et al. 1986; Emerson et al. 1987; Lieber et al. 1987; Knezetic and Felsenfeld 1989). In the course of this work, we identified one DNA sequence motif present near every member of the $\alpha$ - and $\beta$-globin families (Kemper et al. 1987; Evans et al. 1988; Knezetic and Felsenfeld 1989), and we have cloned and characterized the corresponding erythroid-specific transcription factor (Evans and Felsenfeld 1989). This protein is present at every stage of erythroid development and could serve as part of a general activation signal for all members of the globin family.

It is not possible for such a factor to modulate expression of individual members of the globin family; there must be other factors that provide additional, stage-specific control. In this paper we examine in detail elements present in the promoter of the $\beta$-globin gene and describe a factor that appears to be involved in its temporal regulation.

The earliest analysis of the $\beta$-globin promoter revealed the presence of sequence-specific binding factors in the nuclease-hypersensitive domain extending from nucleotide -40 to -240 (Emerson et al. 1985). Footprints obtained in vitro with erythrocyte nuclear extracts, as well as intranuclear footprints (Jackson and Felsenfeld 1985), defined two regions of bound protein at a low level of resolution (Fig. 1). One of these regions consists of a string of $16 \mathrm{G}$ residues; it binds a protein, BGP1, that has been described in detail elsewhere (Lewis et al. 1988). The second footprinted region contains a palindromic sequence (Pal), 25 bp long, ending in the sequence TGAGCC. The last two nucleotides also constitute the beginning of a perfect consensus match (Dierks et al. 1983; Myers et al. 1986) to a 10-bp element, common to most adult $\beta$-globin promoters. This 'globin consensus sequence' continues with the sequence CCACCCTG, often referred to as the CACCC box, shown previously (Dierks et al. 1983; Myers et al. 1986; Cowie and Myers 1988 ) to act as a positive regulator in the promoters of the rabbit and mouse $\beta$-globin genes.

We analyze here the function of the $\mathrm{Pal}$ sequence and the CACCC sequence in $\beta$-globin gene transcriptional regulation. We show that there is a marked change in 


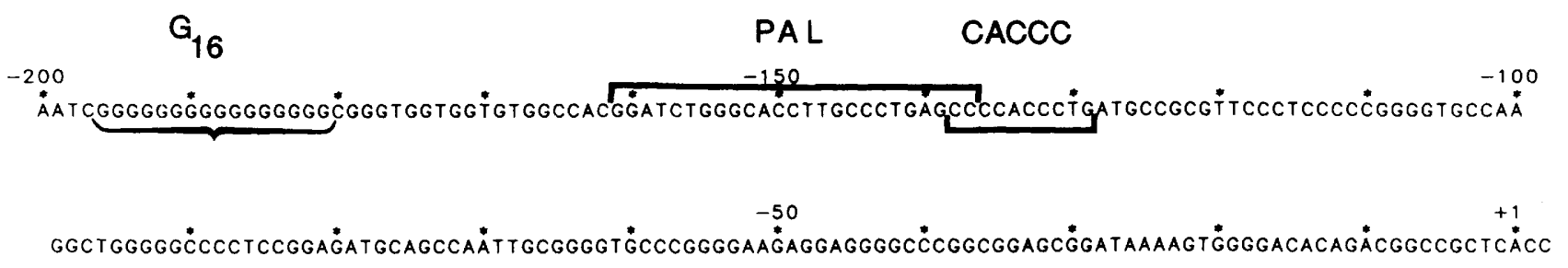

Figure 1. Sequence of the adult $\beta$-globin promoter region indicating the sequence elements analyzed in this study (see text).

the pattern of protein binding to these sites in vivo during erythroid development and that this can be accounted for in terms of changes in the intranuclear concentrations of the proteins and their interactions.

\section{Results}

Patterns of binding to DNA within the nucleus

We began by measuring the binding to the endogenous $\beta$-globin promoter (Fig. 1) within the chicken erythrocyte nucleus, as a function of developmental stage. First, we mapped DNase I digestion patterns at low resolution to confirm the behavior of the hypersensitive domain. Cells were lysed, and the nuclei digested with appropriate amounts of DNase I (see Methods) directly in the lysate, to minimize perturbation of binding patterns within the nucleus. The resulting DNA was analyzed by Southern blotting after digestion with HindIII. The probe used in these experiments lies just $5^{\prime}$ of the HindIII site at +1000 and will detect hypersensitive regions upstream of this site. For example, an analysis of digested DNA isolated from adult cell nuclei is shown in Figure 2a. As reported previously (McGhee et al. 1981), the region of the promoter, including $\sim 200 \mathrm{bp}$ upstream from the cap site, is hypersensitive to the nuclease in these cells. In contrast, the region is not hypersensitive to DNase I in 5-day embryonic nuclei (see below).

After the DNA was fractionated to enrich for $\beta$-globin sequences (Methods), the samples were hybridized to an end-labeled, promoter-specific probe, digested with mung bean nuclease, and electrophoresed on polyacrylamide gels (Jackson and Felsenfeld 1985) to obtain a high resolution map of the promoter's DNase I cleavage pattern within the nucleus.

Comparison of the DNase I digestion patterns of erythrocyte nuclear DNA with the pattern obtained with protein-free genomic DNA reveals the presence of factors bound in vivo to promoter region sequences (Fig. $2 \mathrm{~b})$.

In nuclei from 5-day embryonic cells (lanes 5), in which the $\beta$-globin gene is inactive, the entire upstream domain is $\sim 20$-fold more resistant to DNase I than it is in erythrocytes from later stages in which $\beta$-globin is expressed. Within this region in 5-day cells, the pattern of digestion is quite similar to that of protein-free DNA, with no relatively sensitive or protected sequences. This is consistent with the presence in 5-day cells (primitive lineage) of a nucleosome covering this region (Emerson et al. 1985; Jackson 1986). The nucleosome is no longer present and the DNA is exposed at later stages of devel- opment (definitive lineage cells from 10- or 15-day embryos or adults), but there are several regions within the domain that are resistant to DNase I attack. Sites protected against DNase I cleavage at some stage of erythrocyte development are indicated by arrowheads. The diagram at the right side of Figure $2 b$ shows the positions of the binding sites in vitro for comparison, as determined by earlier footprinting studies (Emerson et al. 1985; Jackson and Felsenfeld 1985).

It is apparent from the data in Figure 2 that within the nucleus there is very little protection of the $\mathrm{Pal}$ site at day 11 of development and almost complete protection in adults; at day 15, there is an intermediate level of protection. The inverse pattern is seen at the CACCC site, which is about one-third occupied at day 11 and is vacant in adults. The BGP1 site is occupied from day 11 through adulthood (see legend to Fig. 2). Densitometry of selected lanes from Figure $2 b$ (see, e.g., Fig. 2c) provides a more quantitative measure of site occupancy, summarized in Table 1.

\section{Patterns of binding to DNA in vitro}

The in vivo footprinting data show that within definitive erythrocyte nuclei there is a gradual replacement of protein bound to the CACCC site with protein bound to the $\mathrm{Pal}$ sequence as erythrocyte development proceeds. To study the binding process further, we compared the above nuclear footprints to DNase I footprints obtained in vitro with nuclear extracts (see Methods) and DNA restriction fragments containing the promoter region. The same samples of lysed erythrocytes that were used for genomic footprinting were also used as a source of nuclear extracts for the in vitro footprinting. The results obtained with extracts from 5-day embryonic and adult cells and from 11-and 15-day cells are shown in Figures 3 and 4, respectively. The shifting pattern of CACCC and $\mathrm{Pal}$ protection resembles that seen within erythrocyte nuclei. The Pal-binding site is increasingly occupied, and the CACCC site less occupied by factors present in nuclear extracts from embryos of increasing age.

\section{Gel mobility assays}

Gel retardation assays (Fried and Crothers 1981; Garner and Revzin 1981) were used as a method of measuring the abundance of the Pal- and CACCC-binding activities in nuclear extracts. Oligonucleotide duplexes, mutated so that only $\mathrm{Pal}$ or CACCC proteins would bind (S. Clark, unpubl.), were mixed with nuclear extracts from 


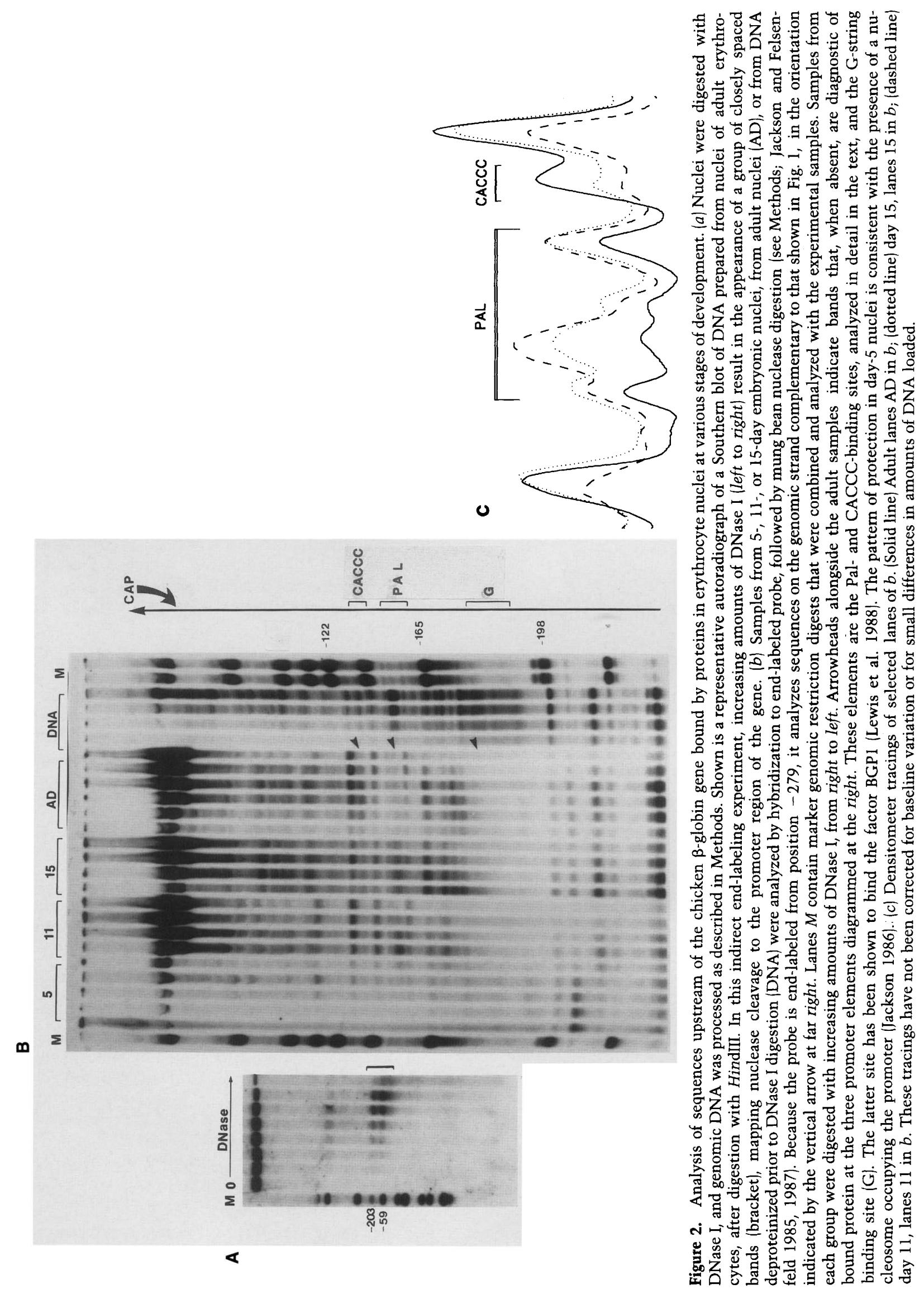


Table 1. Stage-specific variation of occupancy of promoter-binding sites within the nucleus

\begin{tabular}{lcc}
\hline & \multicolumn{2}{c}{ Occupancy $(\%)$} \\
\cline { 2 - 3 } Stage & palindrome & CACCC \\
\hline 11-day embryo & 7 & 36 \\
15-day embryo & 23 & 13 \\
Adult & 83 & 5 \\
\hline
\end{tabular}

various developmental stages and electrophoresed as shown in Figure 5. To assess the integrity of the extracts, each was also tested for the presence of the widely distributed transcription factor Spl (Kadonaga et al. 1986). This assay ensures that gross proteolysis has not occurred and allows us to control for differences in yield during the extraction of nuclear proteins. The quantitative analysis of the results is shown in Table 2. These experiments differ from the in vitro footprinting studies, because the Pal- and the CACCC-binding sites are carried on separate molecules and there can be no interactions between bound proteins (see below). For this

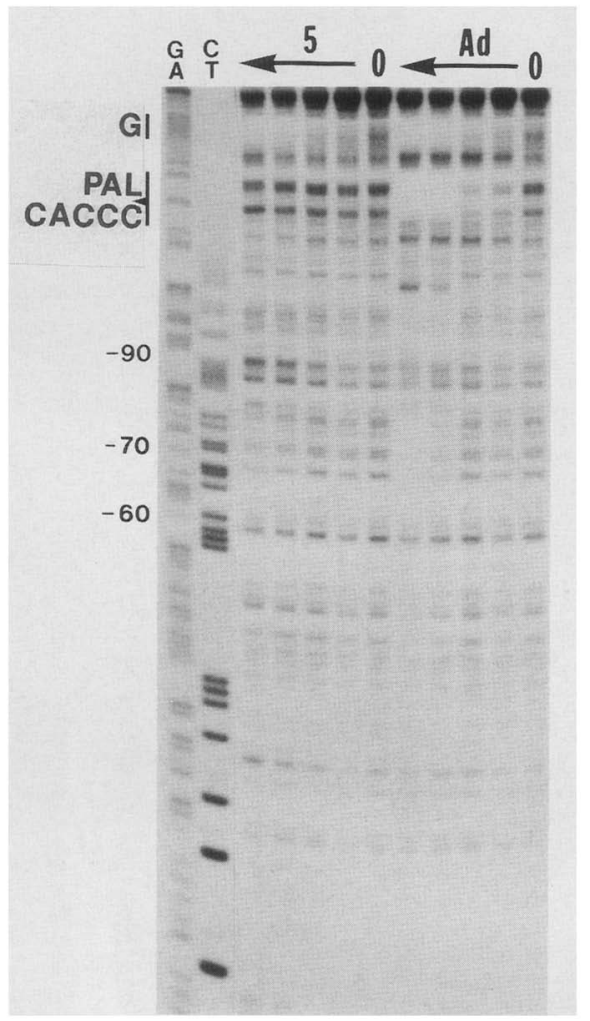

Figure 3. In vitro footprints of the $\beta$-globin promoter region using protein extracts from 5-day embryonic or adult (Ad) chicken erythrocyte nuclei. The probe was $3^{\prime}$-end-labeled at an EagI site at position - 4. It was incubated with increasing amounts (right to left) of extract prior to digestion with DNase I. (Lanes 0 ) Control reactions incubated only with buffer $D$. Lanes $G A$ and $C T$ contain sequencing reactions; the protected elements are shown at left. Binding to the G-string is observed with both 5 -day and adult nuclear extracts. reason, the gel retardation assay provides a more reliable assay for the actual abundance of individual factors.

As determined by the gel mobility assay, the relative abundance of the Pal factor as a function of developmental stage parallels the changes in site occupancy observed in vivo (Table 1). On the other hand, although CACCC occupancy in vivo falls off during development, the gel-binding studies do not show a correspondingly large decrease in the amount of CACCC-binding activity present.

The results obtained using the CACCC probe are somewhat complicated because two separate binding activities compete for the sequence. Competition experiments (not shown) demonstrate that the faster mobility complex (small arrowhead, Fig. 5) is specific to the CACCC site and the slower mobility complex formed with this probe (large arrow) is the result of interaction with Sp1 (see Lewis et al. 1988); the CACCC site binds Spl much more weakly than does a canonical Spl site. The interaction of the CACCC site with $\mathrm{Spl}$ does not affect our measurements of the relative abundance of the principal CACCC-binding activity, because the concentration of DNA is the same in all lanes of Figure 5 and is in vast excess. Under these conditions, the amount of specific complex formed is proportional to the total CACCC-specific protein present. We also note that a roughly constant quantity of $\mathrm{Spl}$ is present at each developmental stage, as judged by the amounts of Sp1binding activity detected using either the Spl probe or the CACCC probe (Fig. 5, large arrows). We have seen no evidence that proteolysis occurs during the time necessary for our experiments. Also, there is no appreciable redistribution of binding activities between nucleus and cytoplasm: When nuclear extracts and cytoplasmic supernatants from 11-or 16-day embryonic erythrocytes were analyzed for Pal-binding activity, $80 \%$ of the activity separated with the nuclei.

\section{Interaction between bound Pal and CACCC proteins}

The gradual replacement of bound CACCC protein by $\mathrm{Pal}$ protein in vivo during development, together with the proximity of the two sites, suggests that binding of protein at one site may have a negative effect on binding at the other. We have carried out a series of experiments to determine whether such anticooperative binding occurs in vitro:

1. Direct examination of DNase I footprints in vitro as a function of increasing protein concentration shows that it is possible to saturate $\mathrm{Pal}$ and CACCC sites simultaneously with large excesses of adult cell extract (Emerson et al. 1985; data not shown). However, footprinting experiments with 11 - and 15-day embryonic extracts provide evidence of some competition between the two factors. As shown in Figure 4, 11-day extracts (lane 3, left) protect the Pal region partially and protect the CACCC site completely. On the other hand, 15day extracts (lane 3 , right) protect Pal completely and CACCC only partially. The amounts of extract used 
Jackson et al.

Figure 4. In vitro footprints with protein extracts from 11- or 15-day embryonic erythrocyte nuclei. The probe was as in Fig. 3. Lanes $C T, A G$, and $O$ are as in Fig. 3; samples in lanes 1-3 were incubated with increasing amounts of protein extract. The remaining samples contained the same amount of protein as used for the sample in lane 3 but also included increasing amounts (left to right) of unlabeled duplex oligonucleotide competitor containing either the CACCC- or the Pal-binding site. Arrows indicate bands that demonstrate more complete binding of $\mathrm{Pal}$ protein as the CACCC protein is removed by cold competitor.

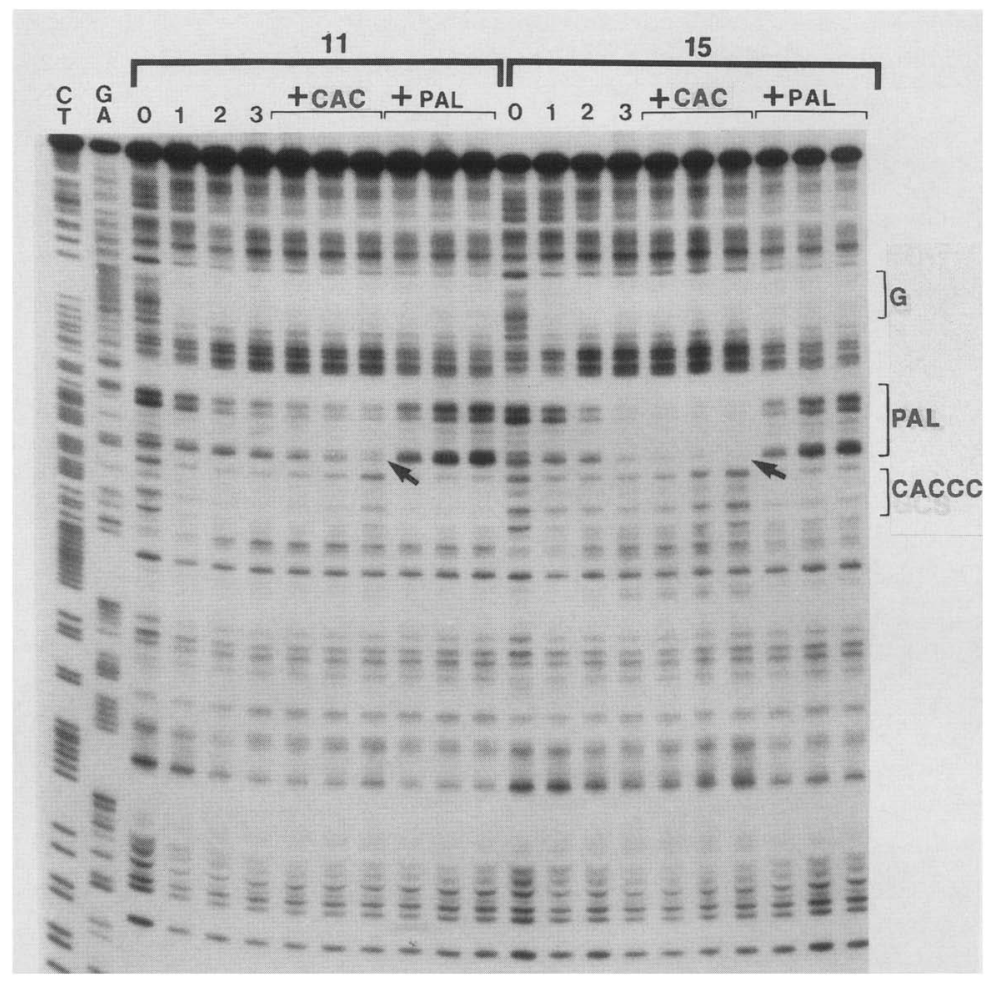

have about the same amounts of CACCC protein, but the 15 -day sample has considerably more $\mathrm{Pal}$ protein (see below and Table 2). We conclude that the binding of $\mathrm{Pal}$ protein reduces the affinity of CACCC protein for its site (and vice versa) but that the effect is not strong.

2. As shown in Figure 4, either the Pal or CACCC protein can be specifically competed by an appropriate unlabeled oligomer containing only one of the two sites. Note that when competitor DNA containing the CACCC site is added together with 11 -day extracts (right-most lane of the 11-day + CAC series), Pal protein binding increases somewhat. This is particularly evident in the disappearance of the strong bands at the bottom of the $\mathrm{Pal}$ region (arrows). A similar (though very weak) response is seen for CACCC binding with 15-day extracts when cold Pal competitor DNA is added. These results

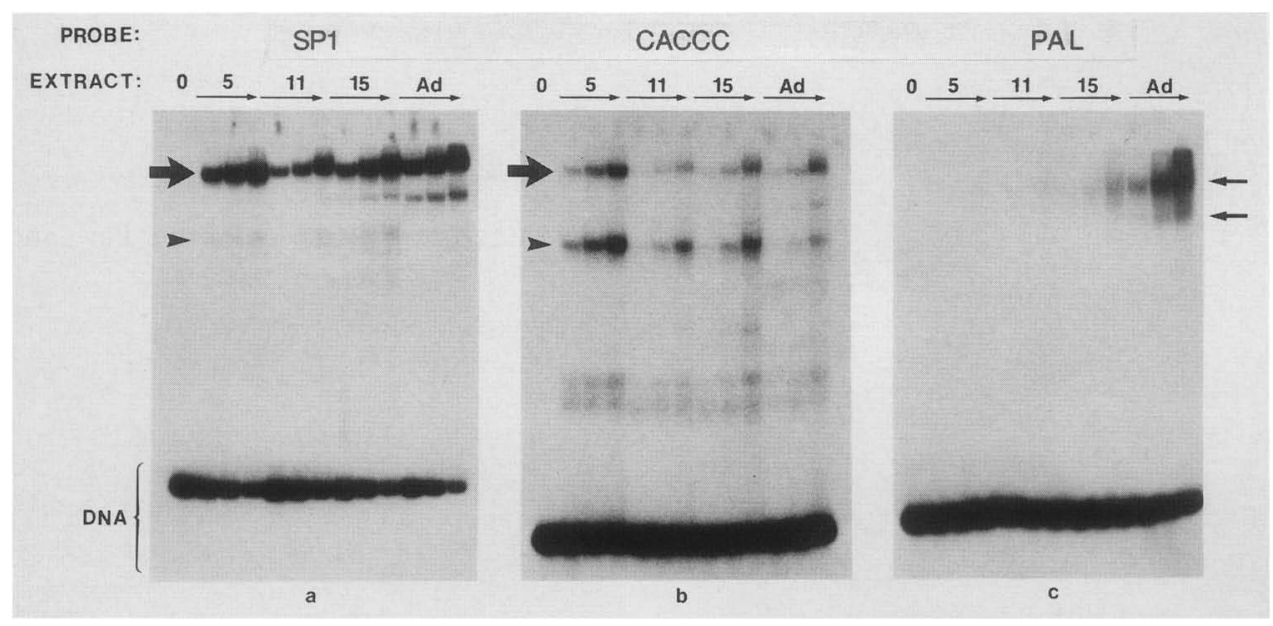

Figure 5. Quantitative analysis of the abundance of Pal- and CACCC-binding activities at various stages of erythroid development. Gel mobility-shift assays were performed using the probes indicated and extracts from 5-, 11-, 15-day embryonic, or from adult (Ad) nuclei. Lanes 0 contain probes incubated only in buffer $D$; in addition, each probe was incubated in the presence of 1,2 , or $4 \mu l$ of extract from each developmental stage (left to right). The Spl probe was used as a control to measure the amount of chicken Sp1, which is expected to be present at all stages in comparable amounts. Spl binds to both the Sp1 and the CACCC probes (large arrows), whereas the CACCC factor (arrowheads) binds only weakly to the Spl probe. The extent of complex formation was quantified by scanning densitometry and normalized relative to Sp1 abundance to obtain estimates of factor binding abundances given in Table 1. 
Table 2. Stage-specific variation of specific promoter-binding activity in vitro from gel mobility shift assays

\begin{tabular}{lcc}
\hline & \multicolumn{2}{c}{ Relative abundance } \\
\cline { 2 - 3 } Stage & palindrome & CACCC \\
\hline 5-day embryo & 1.0 & 1.0 \\
11-day embryo & 6 & 1.2 \\
15-day embryo & 23 & 1.0 \\
Adult & 170 & 0.44 \\
\hline
\end{tabular}

are also consistent with weakly anticooperative binding to the $\mathrm{Pal}$ and CACCC sites.

\section{Tissue specificity of DNA binding factors}

Nuclear extracts from either blood or brain tissue of 10 day chicken embryos were used in the footprinting experiment shown in Figure 6 to determine whether any of the activities that bind to the promoter region are re-

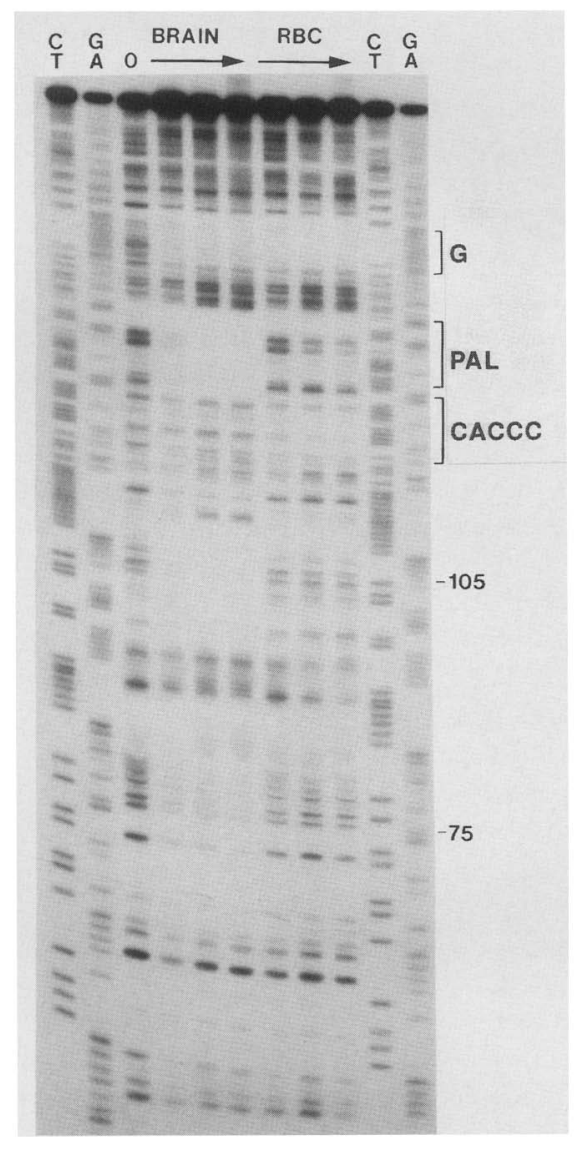

Figure 6. Analysis of $\beta$-globin promoter-binding activities in a nonerythroid tissue. Extracts were prepared from 11-day erythrocytes (RBC) or brain tissue (BRAIN) and used in a DNase I footprint as in Fig. 4. The probe was incubated with increasing amounts of protein (left to right) for each extract. Note that two additional binding sites near positions -105 and -75 , occupied in footprints with extracts from brain (as well as from adult erythrocytes; see Fig. 3), both contain a T/AGCCA sequence that could represent half-sites for the binding of $\mathrm{Pal}$ protein or other factors with NFI-binding specificity. stricted to erythrocytes. The brain extract reveals binding activities to both the G-string and the Pal site but shows no binding to the CACCC. We do not yet know whether the brain factors are identical to those present in erythroid nuclei. In the case of G-string binding, we have previously reported that BGP1 activity is absent from a number of other nonerythroid tissues (Lewis et al. 1988).

Binding at the Pal site in the 10-day brain extract is much more abundant than in the extract from 10-day erythrocytes, comparable to activity detected from adult erythrocytes. Additional binding activities are detected only in the brain extract around positions -105 and -75 [and also in extracts from adult erythrocytes (Fig. 3\|l; these have not yet been investigated further.

A more quantitative analysis comparing binding activities present in the different tissues was carried out by the gel mobility-shift assay, shown in Figure 7. Control oligomers reveal approximately equal amounts of binding activity in both tissues, either to an Spl probe or a nonspecific probe that does not contain sequence from the promoter region (NS). Both extracts also form a similar complex to a probe containing the $\beta$-globin promoter CAAT sequence; the binding activity appears to be about twofold more abundant in the case of the erythrocyte extract. In agreement with the footprinting data, binding activity to the G-string is comparable in the two tissues, but that to the CACCC is much more abundant in the erythrocyte extract. Also in agreement, binding to $\mathrm{Pal}$ is much more abundant in brain extracts than in the 10-day erythrocyte extract, although the mobility of the complex appears to be different. This altered mobility would suggest that the $\mathrm{Pal}$ protein that becomes abundant in later stage erythrocytes is somehow different from that present in 10-day brain (see Discussion). Using a probe for the erythroid-specific factor Eryfl (Evans and Felsenfeld 1989), we can show that binding activity seen in brain extracts is not the result of significant blood contamination.

\section{Function of the upstream binding sites}

To determine what role the Pal- and the CACCCbinding sites play in regulation of globin gene expression, we studied the effect of progressive $5^{\prime}$ deletions on transient expression in primary chicken erythrocytes (Hesse et al. 1986; Lieber et al. 1987; Nickol and Felsenfeld 1988). Plasmid constructions (Fig. 8) contained the chicken $\beta$-globin gene with an insertion in the $5^{\prime}$-untranslated sequence that allow detection of transcripts in S1 nuclease protection assays. The plasmid pUC18ABC containing the entire upstream promoter sequence, starting at -1050 , served as a reference gene in each transfection. Mutant plasmids carried successive deletions from the 5 ' side of the promoter.

It is clear from the results in Figure 8 that deletions up to nucleotide - 165 [and including the G-string protein binding site [Lewis et al. 1988)] have no effect on transcription of the $\beta$-globin gene. However, deletion of the Pal-binding site results in a three- to fourfold increase in 


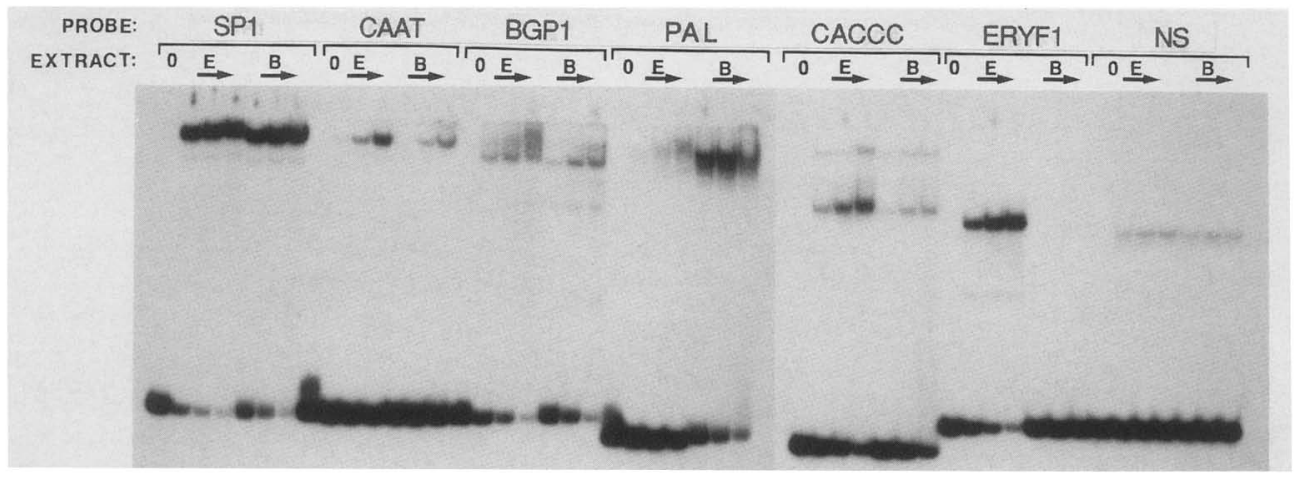

Figure 7. Quantitative comparison of the abundances of binding activities present in erythroid or nonerythroid tissues. Gel mobility-shift assays were performed as in Fig. 5, using various probes as indicated. Each probe was incubated in buffer alone (lanes 0 ), or in the presence of 2, 4, or $6 \mu \mathrm{l}$ (left to right) of protein extract prepared either from nuclei of 11 -day embryonic erythrocytes (E) or from 11-day embryonic brain tissue (B). The Spl and NS (nonspecific) probes are controls to indicate the equivalence of extract preparation. Although not obvious here, the mobility of the complexes formed with the Pal probe in the presence of brain extract are distinct from those formed using the erythroid extract.

transcript abundance (lane -142 ), and a larger deletion that also removes the CACCC site results in a return to slightly greater than baseline transcription levels (lane -122 ). Further deletions to nucleotide -58 maintain this same level of activity, but transcription is completely abolished by deleting down to nucleotide -39 .

These results suggest that the Pal-binding region exerts a negative regulatory effect on transcription, whereas the CACCC site has a positive effect.

\section{Discussion}

We have shown here that the binding of certain factors to the promoter of the chicken $\beta$-globin gene is modulated during development, indicating that the factors play a role in the developmental regulation of the gene.

It is apparent from the data in Figure 8 that the basal activity of the promoter does not require the Pal or CACCC regions but only sequences downstream of nucleotide -58 (in addition to the erythroid-specific enhancer sequences also required in these constructions). However, the data also show that this basal activity can be modulated by factors interacting with $\mathrm{Pal}$ and CACCC. A deletion from the $5^{\prime}$ side that removes the $\mathrm{Pal}$ sequence results in a fourfold stimulation of transcription; a further deletion, removing the CACCC site, restores a slightly higher than baseline transcriptional activity. This result is consistent with a negative regulatory role for the Pal sequence element and a positive role for the CACCC site. Furthermore, in vitro transcription studies carried out with the same deletion mutants reveal quite similar behavior (Emerson et al. 1989). The CACCC sequence has already been shown to serve as a positive element in other $\beta$-globin promoters /Grosveld et al. 1982; Dierks et al. 1983; Charney et al. 1985; Myers et al. 1986; Cowie and Myers 1988).

The stimulation of globin transcription by the CACCC site probably reflects the action of the strongly bound factor revealed in gel mobility-shift experiments. Factors (other than Spl) that bind to the CACCC site can be found in many kinds of cells. They are present, for example, in non-globin-expressing brain tissue (Fig. 7) but are much less abundant than in globin-expressing erythrocytes from the equivalent developmental stage. The general positive regulatory factor $\mathrm{Spl}$ also binds to this site and may affect globin gene expression. The CACCC factor is distinguished from $\mathrm{Spl}$ both by the pattern of complexes it forms in gel mobility shift assays and by its preferential binding to the CACCC site in competition with $\mathrm{Spl}$ sequence (data not shown). The experiments in Figure 5 show that under the conditions of relative abundance present in nuclear extracts, the complex with the CACCC factor is somewhat more abundant than that formed with $\mathrm{Sp} 1$.

Several CACCC-specific binding activities (CACCCbox-binding factors) have been identified previously in human erythroleukemia cells /Gumucio et al. 1988; Mantovani et al. 1988) and chicken erythrocytes (Plumb et al. 1986; Rupp et al. 1988). In addition, a binding activity to a CACCC element has been shown to act cooperatively with a mouse mammary tumor virus glucocorticoid receptor site to mediate transcriptional induction by steroid hormone (Schüle et al. 1988). Some of these activities appear to be ubiquitous, whereas others are more cell-type restricted; therefore, it is unclear what the relation of each is to the CACCC-binding factors being studied.

For example, Xiao et al. (1987) pointed out that the CACCC site is very similar to the GT-I motif of the SV40 enhancer. They showed that both the enhancer element and the CACCC site in the murine major $\beta$ globin gene bind apparently related factors from a variety of cells. Similar to our results concerning the chicken $\beta$-globin CACCC site, at least one binding activity is Spl. A cell-type-specific binding activity to the GT-I motif (TEF2) is distinct from Sp1, and the presence of this latter activity correlates well with the positive transcriptional effect of the cis-acting element (Nomiyama et al. 1987; Xiao et al. 1987; Davidson et al. 1988). We do not yet know whether the erythrocyte 


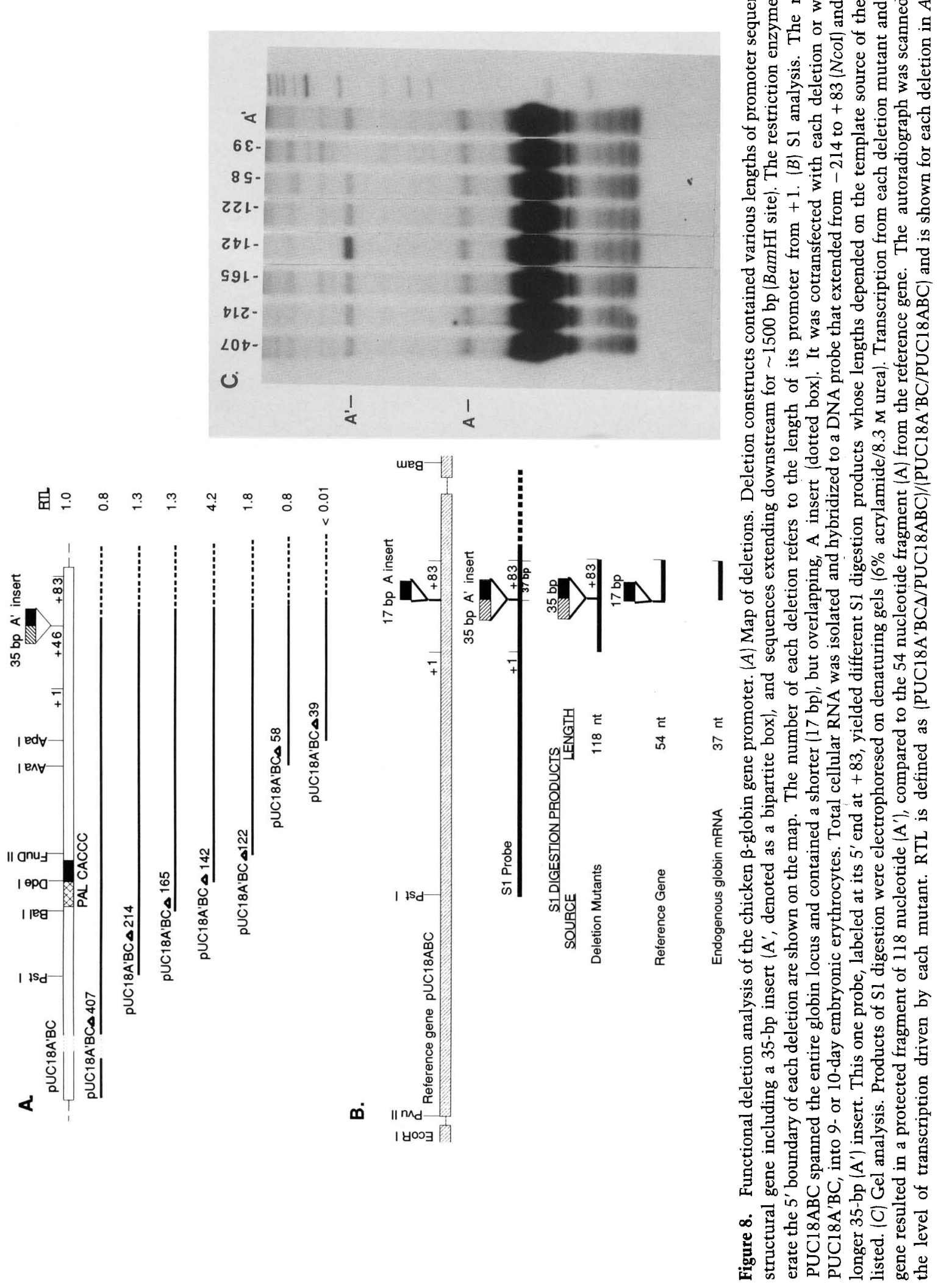

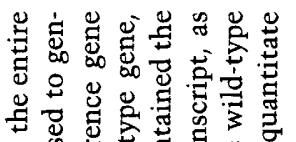

心

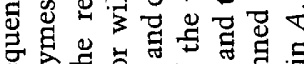

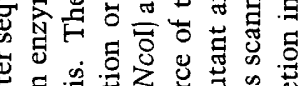

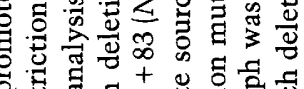

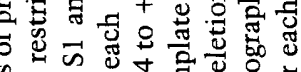

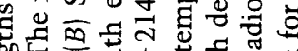

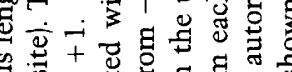

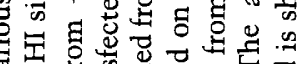

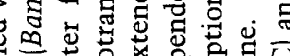

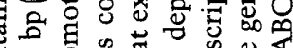

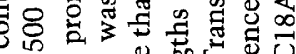

?

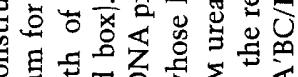

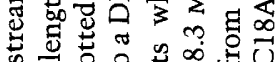

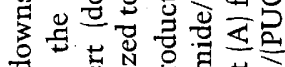

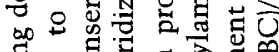

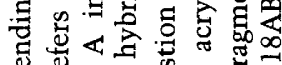

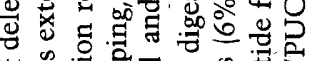

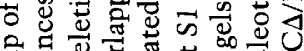

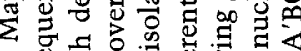

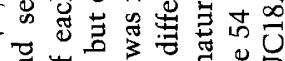

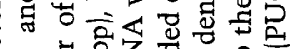

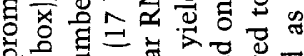

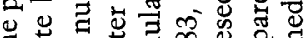

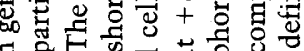

궁.

品

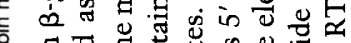

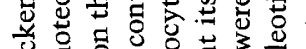

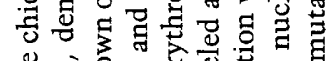

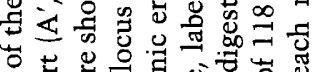

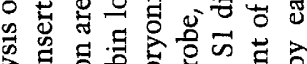

중영

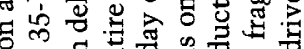

๙

E \&

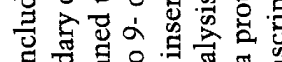

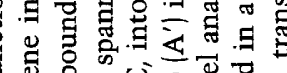

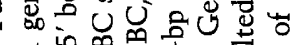

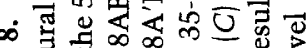

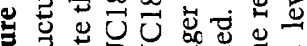

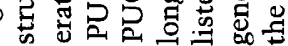


factor that is distinct from $\mathrm{Spl}$ is the same as or related to TEF2.

The palindrome site has considerable sequence similarity to the binding site for human nuclear factor 1 (NF1) (see Fig 1; Rosenfeld and Kelly 1986; Jones et al. 1987). Sippel and his collaborators (Leegwater et al. 1986) have reported that chicken tissues contain at least one factor that binds to a consensus sequence like that of NF1 and have shown that chicken erythrocytes contain a similar factor. It was shown some time ago (Emerson et al. 1985) that human NF1 does not bind tightly to the $\beta$-globin $\mathrm{Pal}$ sequence. However, we find in the reciprocal experiment that the principal adult erythrocyte factor binds somewhat more tightly to a canonical human NF1 site than it does to Pal. Furthermore, the purified erythrocyte protein contains amino acid sequences common to other members of the NF1 family (C. Lewis, unpubl.). Gel retardation studies with the purified protein strongly suggest that it is a distinct, apparently erythroid-specific binding species, although some evidence to the contrary has been reported (Rupp et al. 1988).

The results reported in this paper show that the $\mathrm{Pal}$ binding factor is stage specific. Pal-binding activity is quite low or absent in extracts from 5-day embryonic erythrocytes of the primitive lineage, as judged both from gel retardation and footprint assays (Table 2). Between 6 and 10 times more activity is observed in circulating erythrocytes from 11-day embryos (which are of the definitive lineage), and the activity increases nearly another order of magnitude in the circulating erythrocytes of the adult. Consistent with these observations, the palindrome site within 11-day erythrocyte nuclei is found to be only weakly occupied (in 5-day nuclei of the primitive lineage the site is apparently occupied by a nucleosome). The site is increasingly filled in the nuclei from 15-day cells and from adults. The increasing abundance of palindrome-binding protein measured in vitro thus parallels increasing occupancy of the site in vivo.

The behavior of the CACCC-binding factor is somewhat different. There is a small decrease in its concentration in nuclear extracts as development progresses (Table 2), but there is a larger decrease in occupancy of the site within the nucleus (Table 1). Although this might reflect a difference between conditions in vitro and within the nucleus, the most obvious possible explanation is that the binding of $\mathrm{Pal}$ protein interferes with the binding to the CACCC site, which is immediately adjacent to it.

Other negative regulatory mechanisms of this kind, which depend on displacement of a positive factor, have been reported. Barberis et al. (1987) described a factor (CDP) that inhibits tissue-specific expression of sea urchin histone $\mathrm{H} 2 \mathrm{~B}$ by displacing a protein bound to an overlapping CCAAT sequence. A vertebrate homolog, present in a variety of cell types, binds in vitro to the CCAAT region of the human $\mathrm{A}_{\gamma}$-globin gene (SupertiFurga et al. 1988). Goodbourn and Maniatis (1988) suggested that a similar displacement mechanism may be involved in regulation of the human $\beta$-interferon gene.
Binding of Pal and CACCC proteins is clearly not mutually exclusive in vitro. Footprinting experiments (Emerson et al. 1985) show that it is possible to saturate both sites simultaneously. On the other hand, the footprints in Figure 4 suggest that the binding of the Pal and CACCC proteins is somewhat anticooperative. Can these in vitro data be reconciled with the observation of rather strong apparent mutual exclusion between Pal and CACCC proteins in vivo? Our data are consistent with the following model. (1) The CACCC protein binds to its site with an affinity somewhat greater than that of the Pal protein for its site. At moderate Pal and CACCC protein concentrations, the CACCC site is occupied and the Pal site is partly or completely empty. (2) The binding of either protein to its site is reduced but not completely blocked when the other site is occupied. (3) The concentration of $\mathrm{Pal}$ protein increases late in development sufficiently to force occupancy of the Pal site and displacement of the CACCC protein.

We have carried out calculations (see Appendix) in which we assigned reasonable values to the concentrations of the various components and to their binding constants, consistent with the data and the assumptions outlined above. The calculated results can be made to reproduce quite well the observed experimental behavior of the system.

Our results appear to establish a negative regulatory role for the Pal protein when it is bound to the Pal site. Deletion of the Pal sequence alone increases globin gene transcription rates. Because deletion of both $\mathrm{Pal}$ and CACCC returns the transcription rate to its baseline level, it seems likely that $\mathrm{Pal}$ protein functions primarily by reducing binding to the CACCC site. It should be pointed out that our model is also consistent with the footprint results of Emerson et al. (1989), who concluded that the Pal and CACCC factors bind independently (these workers referred to CACCC as CON). Our explanation of the data is different. As shown above and in the Appendix, simultaneous occupancy of both the CACCC and Pal sites can occur at sufficiently high factor concentrations even though CACCC and Pal proteins bind anticooperatively. Our footprint results and those of Emerson et al. (1989) therefore are not inconsistent with the anticooperative model, which our other data support. The further observation of Emerson et al. (1989) that addition of a protein (human CTF) displacing the Pal protein also relieves inhibition suggests, as one possibility, that CTF does not interfere with CACCC protein binding.

The Pal factor is absent from erythrocytes of the early embryo, and it (or, more precisely, its binding activity) is in greatest abundance in circulating erythrocytes of the adult. This, together with our observation that the Pal element has a negative effect on transcription, led us to suggest that the $\mathrm{Pal}$ factor functions during erythrocyte development to help shut down expression of the $\beta$ globin gene as cells of the definitive lineage reach maturity, though the magnitude of this effect in developing chickens remains to be determined. It is also possible that the Pal factor acts as a repressor in the regulatory 
domains of other genes. We note that there is a Palbinding site in the promoter of the $\beta$-hatching globin gene (Plumb et al. 1986; Rupp et al. 1988), which must shut off expression as embryonic development comes to a close. Furthermore, there is a second binding site for an uncharacterized protein immediately adjacent to the Pal site. The hatching gene Pal site is of higher affinity than that of $\beta$-globin and should become occupied at lower Pal protein concentrations (hence, earlier in development).

In any case, the binding of the Pal protein to the NF1binding site in the $\beta$-globin promoter appears to be an example of a mechanism that operates on only a subset of the globin gene family. This class of mechanisms is distinctly different from that involving the factor Eryfl, a more universal activator protein that can serve as a positive signal for all members of the globin family (Evans et al. 1988). Given the existence of such a general erythroid-specific factor, it seems reasonable that other factors must exist to modulate expression of the individual genes. The Pal protein appears to be one such factor.

\section{Methods}

Protein and genomic DNA sample preparation

Nuclei were prepared and used simultaneously either for digestion of genomic DNA (in vivo footprints) or for preparation of nuclear protein extracts (in vitro footprints and binding assays). This was intended to minimize artifactual differences between protein samples extracted from nuclei and samples analyzed directly for the presence of bound proteins in vivo.

Erythrocytes were obtained by bleeding 11-or 15-day chicken embryos or adult hens. To obtain red blood cells from 5-day embryos, whole embryos were bled in PBS by gentle agitation in a Waring Blendor operated at low speed. After filtering through cheesecloth, erythrocytes were pelleted twice through lymphocyte separation medium (LSM, Organon Teknika). Nuclei were then prepared by hypotonic lysis as described (Evans et al. 1988). One-half of each sample was pelleted for $20 \mathrm{~min}$, after which nuclear proteins were extracted, as described (Evans et al. 1988), and dialyzed into buffer D: 20 mM HEPES (pH 7.9), $100 \mathrm{~mm} \mathrm{KCl}, 0.2 \mathrm{~mm}$ EDTA, $20 \%$ glycerol, $0.5 \mathrm{~mm}$ dithiothreitol (DTT), $0.5 \mathrm{~mm}$ phenylmethylsulfonyl fluoride, 0.5 $\mu \mathrm{g} / \mathrm{ml}$ leupeptin, and $0.7 \mu \mathrm{g} / \mathrm{ml}$ pepstatin A (Dignam et al. 1983). While the nuclei were being pelleted, the other half of the sample of lysed cells was divided into aliquots and digested with one-seventh volume of twofold dilutions of DNase I (Pharmacia) in lysis buffer plus $7 \mathrm{mM} \mathrm{CaCl}$. Control samples were incubated without DNase I. After $20 \mathrm{~min}$ of digestion at $0^{\circ} \mathrm{C}$, the reaction was stopped and DNA was prepared as described (Jackson and Felsenfeld 1987).

The DNase I concentrations required to achieve sufficient cleavage within the $\beta$-globin promoter region varied, depending on the tissue being digested. The ranges of nuclease required for the digestions shown in Figure 2 are as follows: 5-day erythrocytes, 175-1400 units of DNase I per milligram of genomic DNA; 11-day erythrocytes, 22-175 U/mg; 15-day erythrocytes, $6-45 \mathrm{U} / \mathrm{mg}$; adult erythrocytes, $6-90 \mathrm{U} / \mathrm{mg}$; protein-free DNA, $0.26-4 \mathrm{U} / \mathrm{mg}$.

Proteins were prepared from 11-day embryonic brain tissue by manual dissection of brains after the embryos had been thoroughly bled. Erythrocytes were further washed from the tissue by mincing the brains and allowing the fragments to settle several times in fresh PBS. Tissue was broken up by several gentle strokes of a Teflon Dounce homogenizer in PBS, and cell number was estimated prior to extract preparation by lysing a small sample in $0.1 \%$ SDS followed by measurement of $A_{260}$ to determine the nucleic acid concentration.

\section{Genomic footprints}

To assay the extent of DNase I digestion in the region of the $\beta$-globin gene, a portion of each DNA sample was digested with HindIII and analyzed by Southern blotting. The blots were probed with a fragment that extends from the HindIII site at position +1062 to the $B g I I I$ site at position +582 . This makes it possible to monitor both the disappearance of the full-length HindIII fragment containing the promoter region and the appearance of discrete subfragments caused by digestion in the hypersensitive promoter region (see McGhee et al. 1981). Samples that showed similar amounts of digestion (several from each age group) were then analyzed at high resolution. Because this region is not hypersensitive to DNase I in 5-day nuclei, the loss of the full-length HindIII fragment was used as an indicator of the level of digestion in these cells.

Samples in which the DNase I cleavage sites were to be mapped at high resolution were purified further. This purification increases the abundance of globin sequence about sevenfold and consequently increases the sensitivity of the high resolution mapping. Each sample was digested to completion with SacI (which isolates the promoter region on a $1.47-\mathrm{kb}$ SacI fragment) and electrophoresed through a $1.2 \%$ agarose gel. DNA smaller than $\sim 3 \mathrm{~kb}$ was electrophoresed onto DE81 paper (Whatman) and eluted by incubation in a $3 \mathrm{M} \mathrm{NaCl}$ solution. Genomic DNA that had not been digested with DNase I was also processed in this manner and then was used to generate restriction digest size standards. After dialysis to remove the $\mathrm{NaCl}$, samples were concentrated by butanol extraction, precipitated with isopropanol, and resuspended in TE, and the yields quantitated by measurement of $A_{260}$. Fifteen micrograms of each sample was then digested to completion with BstNI (which cuts just outside of the region to be analyzed) to decrease the size of the genomic DNA and minimize displacement of probe by genomic DNA during subsequent hybridization.

Cleavage sites within each sample were then mapped, as described by Jackson and Felsenfeld $(1985,1987)$, by hybridization to an end-labeled, single-stranded probe followed by mung bean nuclease digestion. The probe used in these hybridizations was end-labeled and extended on a single-stranded $\beta$-globin/M13 recombinant phage DNA template from a 15-nucleotide synthetic oligonucleotide primer starting at position -279 (relative to the $\beta$-globin mRNA cap site) and extending to a BglI site at position +126 ; it contained $\sim 40$ nucleotides of $\left[\alpha-{ }^{-32} \mathrm{P}\right] \mathrm{dNTP}$ (3000 Ci/mmole) at the $5^{\prime}$ end.

\section{In vitro footprinting}

Restriction fragments were end-labeled and purified from preparative polyacrylamide gels by standard techniques (Maniatis et al. 1982). Probes (0.5-1.0 ng) were incubated on ice for 10 min with $1.0 \mu \mathrm{g}$ poly[d(I-C)] (Boehringer-Mannheim) and various amounts of protein extract in $50 \mu \mathrm{l}$ at a final concentration of $0.5 \times$ buffer $\mathrm{D}$ containing $10 \mathrm{mM} \mathrm{MgCl}_{2}$ and $5 \%$ PEG 8000. A $50 \mu \mathrm{l}$ sample of $10 \mathrm{mM} \mathrm{MgCl}_{2}$ and $5 \mathrm{mM} \mathrm{CaCl}_{2}$ was added immediately prior to addition of $1 \mu \mathrm{l}$ of diluted DNase I stock. The appropriate DNase I concentration was determined empirically and was usually in the range $0.04-0.3 \mathrm{U} / \mu \mathrm{l}$. After a 
1-min digestion at room temperature, the reactions were stopped by addition of $100 \mu \mathrm{l}$ of $200 \mathrm{mM} \mathrm{NaCl}, 20 \mathrm{~mm}$ EDTA, $1 \%$ SDS, and $250 \mu \mathrm{g} / \mathrm{ml}$ yeast tRNA. Samples were extracted twice with $1: 1$ phenol/chloroform-isoamyl alcohol $(24: 1)$ and once with chloroform-isoamyl alcohol alone, and ethanolprecipitated. DNA was then resuspended in $80 \%$ formamide loading buffer and electrophoresed through $6 \%$ urea-polyacrylamide gels, alongside sequencing ladders made from undigested material (Maxam and Gilbert 1980).

\section{Mobility-shift assays}

Gel mobility-shift assays were performed as described (Evans et al. 1988). For most competition experiments, the unlabeled duplex was added prior to addition of protein.

The sequences of the oligonucleotide probes used in this study are as follows, with the relevant binding site underlined (only the top strand is shown):

Spl: AATTGCAGAGCTGGGAATCCTAACTGGGCGGAGTTATGCTGGTGGTGTGG CACCC: GGCCGCGGATCACCGCACCTTGCCC TGAGCCCCACCCTGATGA Pal: GGCCGCGGATCTGGGCACCTTGCCCTGAGCCACGCGTATTCGA

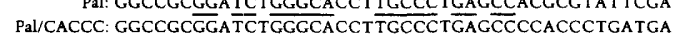
CAAT: GGGGTGCCA A CAAT: GGGGTGCCAAGGCTGGGGGCCCCTCCGGAGATGCAGCCAATTCCGGGGTGCCC
G: AATTGCAGAGCTGGGAATCGGGGGGGGGGGGGAAAGGTGGTGGTGTGG ERYH: AGCTTCGGTTGCAGATAAACATTGAATTCA

NS: AATTGCAGAGCTGGGAATCCTACCTTGAAGTCGAAGTGCTGGTGGTGTGG

\section{Construction of deletion mutants}

For accurate quantitation of RNA synthesis from the deletion mutants, it is necessary to distinguish RNA transcribed off the transfected DNA from the high background of endogenous globin mRNA. To accomplish this, a 35-bp insert $\left(A^{\prime}\right\rangle$ was cloned into the $\beta$-globin structural gene at the $R s a I$ site $(+46)$ in the center of the transcribed but untranslated leader sequence. The resulting plasmid, pUC18A'BC, contains the upstream promoter (from the EcoRI site at -1050 ), the structural gene with the $35-\mathrm{bp} \mathrm{A}^{\prime}$ insert, and $1.5 \mathrm{kbp}$ of $3^{\prime}$-flanking sequences extending downstream to the BamHI site, thereby encompassing the globin enhancer. The $5^{\prime}$ deletions were generated from the parent $\mathrm{pUC} 18 \mathrm{~A}^{\prime} \mathrm{BC}$ by digestion at the appropriate restriction sites within the promoter region (Fig. 8A), blunting the overhanging ends with $\mathrm{T} 4$ polymerase or Klenow fragment, and ligating EcoRI linkers so that adjoining plasmid sequences are identical. The promoter regions of all deletion constructs were confirmed by DNA sequencing. These are the identical plasmids used in the in vitro transcription studies of Emerson et al. (1989).

A shorter insert $(A)$, which shares the same $3^{\prime}$-flanking $17 \mathrm{bp}$ with the longer $A^{\prime}$ insert, was cloned into the wild-type globin gene at the same site as the insert in pUC18. $\mathrm{A}^{\prime} \mathrm{BC}$; all other sequences within the two test genes were identical. The resulting construction, pUC18ABC, was used as a reference gene and was cotransfected with each deletion mutant. The overlapping design of reference and test globin genes enabled us to use the same labeled probe in nuclease S1 assays to quantitate both deletion and wild-type promoter activity in the same cell population.

\section{Primary erythrocyte transfections}

Definitive erythrocytes isolated from the peripheral circulation of 9- or 10-day chicken embryos were osmotically shocked and transfected as described previously (Hesse et al. 1986), except that the volume for each reaction was increased 10 -fold to facilitate subsequent RNA extractions. In a standard reaction, erythrocytes (an original 5-ml volume; $3.5 \times 10^{8}$ to $3.8 \times 10^{8}$ cells $/ \mathrm{ml} ; 23-25 A_{412} / \mathrm{ml}$ ) were pelleted and osmotically shocked in $10 \mathrm{ml}$ of $0.25 \mathrm{M} \mathrm{NH}_{4} \mathrm{Cl}$ for $40 \mathrm{~min}$ at $25^{\circ} \mathrm{C}$ (a release of $25 \%$ of total hemoglobin). The cells were transfected with 5 $\mathrm{ml}$ of a solution containing both deletion and reference gene DNA each at $1.5 \mu \mathrm{g} / \mathrm{ml}$. The total DNA concentration 13 $\mu \mathrm{g} / \mathrm{ml}$ l) was within the linear range for response of RNA synthesis to input DNA. After transfection, the cells were washed with $10 \mathrm{ml} \mathrm{L}-15$ media without serum and were finally resuspended in $3 \mathrm{ml} \mathrm{L}-15$ media containing $30 \%$ chicken serum for $48 \mathrm{hr}$ of incubation at $37^{\circ} \mathrm{C}$.

\section{RNA isolation and S1 analysis}

After incubation, erythrocytes were pelleted and resuspended in $1 \mathrm{ml} 50 \%$ guanidinium chloride/imidazole solution, and total cellular RNA was isolated by pelleting through a $\mathrm{CsCl}$ cushion as described (Stevens et al. 1987). The RNA pellets were resuspended in $50 \mathrm{mM}$ sodium acetate $(\mathrm{pH} 5.2), 0.5 \%$ sodium dodecyl sulfate, $5 \mathrm{~mm}$ EDTA, heated at $65^{\circ} \mathrm{C}$ for 10 min, extracted with phenol/chloroform, and ethanol-precipitated. For the S1 nuclease protection assays, one-half of each total RNA sample was annealed to a 332-bp DNA fragment $(-214$ to +83$)$ that contained the $35-$ bp A $^{\prime}$ insert at +46 of the $\beta$-globin gene. After hybridization at $42^{\circ} \mathrm{C}$ for $6 \mathrm{hr}$, the samples were digested with $\mathrm{S} 1$ nuclease $\left(250 \mu / \mathrm{ml}, 37^{\circ} \mathrm{C}, 30 \mathrm{~min}\right)$. Conditions and buffers for hybridization and S1 digestion were as described (Maniatis et al. 1982). The three different products of the nuclease digestion are shown in Figure 8B. RNA synthesized from the deletion mutants spans the full length of the probe from the cap site to +83 ( 110 nucleotides), whereas transcripts directed by the reference gene are complementary to the labeled $\mathrm{A}^{\prime}$ probe for only 54 nucleotides, and the $\beta$-globin endogenous mRNA yields an even shorter 37-nucleotide-long product. Transient expression experiments have been performed several times to confirm the results of Figure 8; the relative transcription (RTL) values in Figure $8 \mathrm{a}$ are from the particular experiment shown in Figure 8c.

\section{Appendix}

To understand better the protein-DNA interactions described above, we analyzed a simple model system in which palindrome protein $(P)$ and CACCC protein $(C)$ bind to a DNA molecule $(D)$ containing sites for both proteins. To make this calculation, we chose 'reasonable' values for the binding constants and intranuclear concentrations of the components: The specific and nonspecific binding constants and the concentrations of factors we used are in the range found in eukaryotic cells (see, e.g., Emerson et al. 1985). However, the purpose of this calculation is to show that the experimentally observed behavior is qualitatively consistent with our model and that some behavior that might seem paradoxical is to be expected. The exact values we assume or obtain from the calculation are not to be taken literally; many other sets of values we could have chosen are consistent with the general behavior described here.

The reactions and their equilibrium constants to be considered are as follows:

$$
\begin{aligned}
D+P & =D P\left(K_{\mathrm{P}}\right) \\
D+C & =D C\left(K_{\mathrm{C}}\right) \\
D P+C & =D P C\left(K_{\mathrm{PC}}\right) \\
D C+P & =D P C\left(K_{\mathrm{CP}}\right)
\end{aligned}
$$

where $D P, D C$, and $D P C$ are the three kinds of complexes that can form.

We assign reasonable values to the specific binding constants, setting $K_{\mathrm{P}}=0.9 \times 10^{11}$ and $K_{C}=1.5 \times 10^{11}$. (The use 
of slightly unequal values for these two constants gives somewhat better results.) The experiments show that there is interference between binding of $P$ and $C$ to the same molecule of $D$. This is equivalent to saying that $K_{P C}<K_{C}$ (i.e., the affinity constant for binding $C$ to a molecule already carrying $P$ is less than the constant for binding $C$ to a naked site). It must then also be true that $K_{C P}<K_{p}$; fixing the first three constants also fixes the fourth. We assume here that $K_{P C}=0.0005 K_{C}$, corresponding to moderate interference.

When considering binding within the nucleus, it is also necessary to consider nonspecific binding, which sequesters most of the protein. We assume that the nonspecific constant is $10^{4}$ for both $P$ and $C$.

We used these equations to calculate the expected change in Pal site occupancy within the nucleus as $P$ concentration changes during development (Fig. 9). For simplicity, we have kept $C$ concentration constant; the results would be even more striking if $C$ were allowed to decrease somewhat, as it does in vivo. The results show that as $P$ concentration rises during development, the Pal site becomes filled and the CACCC site becomes vacant, consistent with the intranuclear footprint data (Fig. 9).

The results of footprinting experiments in vitro are somewhat different. In Figure 10, we introduce the much larger specific DNA concentrations that might be used in such an experiment. Two kinds of results are obtained. If the concentration of one component (in this case, $C$ ) is held constant and the other $(P)$ is increased, a displacement reaction is observed (Fig. 10A), somewhat like that seen in Figure 9, except that at high $P$ concentrations the occupancy of CACCC does not drop to zero, but approaches a lower limit. (The exact value of this limit depends on the numerical values of the constants.) This type of behavior is observed experimentally. The second type of behavior is seen if the concentrations of Pal and CACCC protein are kept equal to one another and allowed to increase. In that case (Fig. 10B), both sites becomes saturated, as observed for in vitro footprints obtained at high concentrations of nuclear extract.

INTRANUCLEAR COMPETITION OF PAL AND CACCC PROTEINS

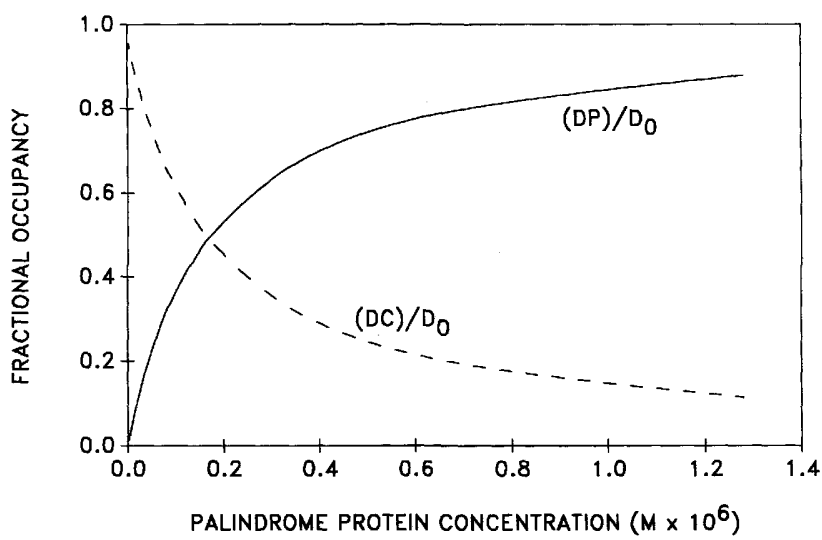

Figure 9. Effect of increasing $\mathrm{Pal}$ protein concentration on $\mathrm{Pal}$ and CACCC site occupancy within the nucleus. The assumed values of the binding constants are given in the Appendix. Intranuclear concentrations of specific and nonspecific binding sites were calculated, assuming a nuclear diameter of $5 \times 10^{-4}$ $\mathrm{cm}$. The concentration of CACCC protein was fixed at $2.5 \times 10^{-7} \mathrm{M}(\sim 5000$ molecules per nucleus). Pal protein concentration has been allowed to vary in a way consistent with the observed increase in its intranuclear abundance during development (see Discussion).
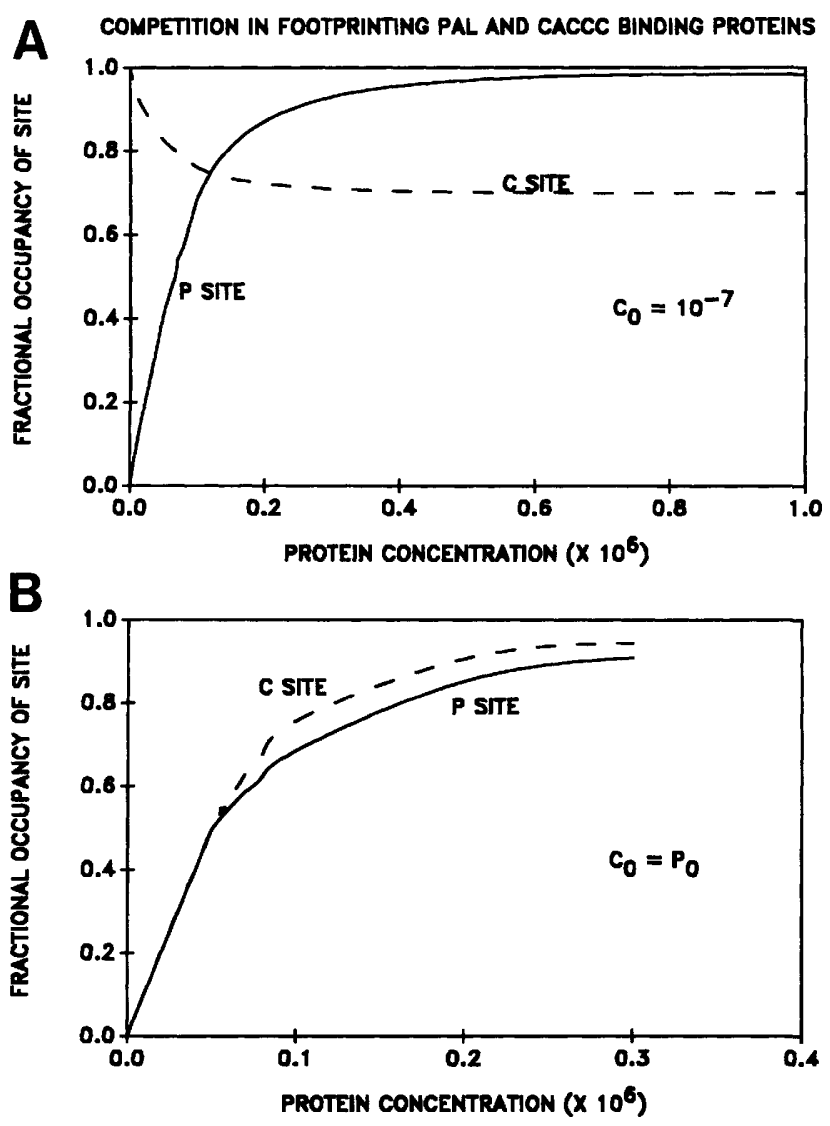

Figure 10. Effect of varying concentrations of binding proteins on site occupancy under in vitro footprinting conditions. $(A)$ Binding site and CACCC protein concentrations are fixed at $10^{-7} \mathrm{M}$. Pal protein concentration is allowed to vary. $(B)$ Binding site concentration is the same as in $A$, but both CACCC and Pal protein concentrations are allowed to vary (Pal- and CACCC-binding protein concentrations are kept equal to one another).

The final calculation concerns the behavior of transfected plasmids. It seemed paradoxical that the deletion of the Pal region (Fig. 8) should have an effect on transcriptional activity in 9-day cells, which do not have detectible amounts of the protein bound at that site within the nucleus. Calculation shows, however, that when the nuclear equilibrium is perturbed by the introduction of large amounts of specific binding site, enough $\mathrm{Pal}$ protein is bound to permit an effect on transcription. Thus, we predict that if 4000 copies of the test plasmid are introduced into each cell and if the nucleus also contains that number of $\mathrm{Pal}$ and CACCC protein molecules, deletion of the Pal site will result in a $50 \%$ increase in the occupancy of the $C$ site. This is somewhat lower than the fourfold increase reported in Figure 8; we could come closer to the experimental value by adjusting parameters further, but we present this calculation only to show that all of the observed behavior can be explained by simple assumptions about the reactions that occur.

\section{Acknowledgments}

We wish to thank Drs. S. Clark and C. Lewis for allowing us to make use of unpublished data. 


\section{References}

Barberis, A., G. Superti-Furga, and M. Busslinger. 1987. Mutually exclusive interaction of the CCAAT-binding factor and of a displacement protein with overlapping sequences of a histone gene promoter. Cell 50: 347-359.

Bruns, G.A. and V.M. Ingram. 1973. The erythroid cells and hemoglobins of the chick embryo. Phil. Trans. R. Soc. London Ser. B 266: 225-305.

Charney, P., P. Mellon, and T. Maniatis. 1985. Linker scanning mutagenesis of the $5^{\prime}$-flanking region of the mouse $\beta$-majorglobin gene: Sequence requirements for transcription in erythroid and non-erythroid cells. Mol. Cell. Biol. 5: 14981151.

Collins, F.S. and S.M. Weissman. 1984. The molecular genetics of human hemoglobin. Prog. Nucleic Acid Res. Mol. Biol. 31: 315-462.

Cowie, A. and R.M. Myers. 1988. DNA sequences involved in transcriptional regulation of the mouse $\beta$-globin promoter in murine erythroleukemia cells. Mol. Cell. Biol. 8: 31223128.

Davidson, I., J.H. Xiao, R. Rosales, A. Staub, and P. Chambon. 1988. The HeLa cell protein TEF-l binds specifically and cooperatively to two SV40 enhancer motifs of unrelated sequence. Cell 54: 931-942.

Dierks, P., A. Van Ooyen, M.D. Cochran, C. Dobkin, J. Reiser, and C. Weissmann. 1983. Three regions upstream from the cap site are required for efficient and accurate transcription of the rabbit $\beta$-globin gene in mouse 3 T 6 cells. Cell 32: 695-706.

Dignam, J.D., R.M. Lebowitz, and R.G. Roeder. 1983. Accurate transcription initiation by RNA polymerase II in a soluble extract from isolated mammalian nuclei. Nucleic Acids Res. 11: $1475-1489$.

Emerson, B.M., C.D. Lewis, and G. Felsenfeld. 1985. Interaction of specific nuclear factors with the nuclease-hypersensitive region of the chicken adult $\beta$-globin gene: Nature of the binding domain. Cell 41: $21-30$.

Emerson, B.M., J.M. Nickol, and T.C. Fong. 1989. Erythroidspecific activation and derepression of the chick $\beta$-globin promoter in vitro. Cell 57: 1189-1200.

Emerson, B.M., J.M. Nickol, P.D. Jackson, and G. Felsenfeld. 1987. Analysis of the tissue-specific enhancer at the $3^{\prime}$ end of the chicken adult $\beta$-globin gene. Proc. Natl. Acad. Sci. 84: 4786-4790.

Evans, T. and G. Felsenfeld. 1989. The erythroid-specific transcription factor Eryfl: A new finger protein. Cell 58: 877885.

Evans, T., M. Reitman, and G. Felsenfeld. 1988. An erythrocyte specific DNA-binding factor recognizes a regulatory sequence common to all chicken globin genes. Proc. Natl. Acad. Sci. 85: 5976-5980.

Fried, M. and D.M. Crothers. 1981. Equilibria and kinetics of lac repressor-operator interactions by polyacrylamide gel electrophoresis. Nucleic Acids Res. 9: 6505--6509.

Garner, M.M. and A. Revzin. 1981. A gel electrophoresis method for quantifying the binding proteins to specific DNA regions. Applications to components of the E. coli lactose operon regulatory system. Nucleic Acids Res. 9: 30473060.

Goodbourn, S. and T. Maniatis. 1988. Overlapping positive and negative regulatory domains of the human $\beta$-interferon gene. Proc. Natl. Acad. Sci. 85: 1447-1451.

Grosveld, G.C., E. deBoer, C.K. Shewmaker, and R.A. Flavell. 1982. DNA sequences necessary for the transcription of the rabbit $\beta$-globin gene in vivo. Nature 295: 120-126.
Gumucio, D.L., K.L. Rood, T.A. Gray, M.F. Riordan, C.I. Sartor, and F.S. Collins. 1988. Nuclear proteins that bind the human $\gamma$-globin gene promoter: Alterations in binding produced by point mutations associated with hereditary persistence of fetal hemoglobin. Mol. Cell. Biol. 8: 5310-5322.

Hesse, J.E., J.M. Nickol, M.R. Lieber, and G. Felsenfeld. 1986. Regulated gene expression in transfected primary chicken erythrocytes. Proc. Natl. Acad. Sci. 83: 4312-4316.

Jackson, P.D. 1986. 'Tissue-specific gene regulation and the structural differentiation of the adult chicken $\beta$-globin

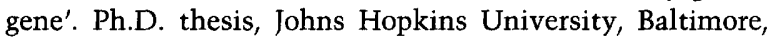
Maryland.

Jackson, P.D. and G. Felsenfeld. 1985. A method for mapping intranuclear protein-DNA interactions and its application to a nuclease hypersensitive site. Proc. Natl. Acad. Sci. 82: 2296-2300.

- 1987. In vivo footprinting of specific protein/DNA interactions. Methods Enzymol. 152: 735-755.

Jones, K.A., J.T. Kadonaga, P.J. Rosenfeld, T.J. Kelly, and R. Tiian. 1987. A cellular DNA-binding protein that activates eukaryotic transcription and DNA replication. Cell 48: 7989.

Kadonaga, J.T., K.A. Jones, and R. Tjian. 1986. Promoter-specific activation of RNA polymerase II transcription by Spl. Trends Biochem. Sci. 11: 20-23.

Kemper, B., P.D. Jackson, and G. Felsenfeld. 1987. Proteinbinding sites within the $5^{\prime} \mathrm{DN}$ ase I-hypersensitive region of the chicken $\alpha^{\mathrm{D}}$-globin gene. Mol. Cell. Biol. 7: 2059-2069.

Knezetic, J.A. and G. Felsenfeld. 1989. Identification and characterization of a chicken $\alpha$-globin enhancer. Mol. Cell Biol. 9: 893-901.

Leegwater, P.A.J., P.C. Vander Vliet, R.A. Rupp, J. Nowock, and A.E. Sippel. 1986. Functional homology between the sequence-specific DNA-binding proteins nuclear factor I from Hela Cells and the TGGCA protein from chicken liver. EMBO I. 5: 381-386.

Lewis, C.D., S.P. Clark, G. Felsenfeld, and H. Gould. 1988. An erythrocyte-specific protein that binds to the poly(dG) region of the chicken $\beta$-globin gene promoter. Genes Dev. 2: $863-873$.

Lieber, M.R., J.E. Hesse, J.M. Nickol, and G. Felsenfeld. 1987. The mechanism of osmotic transfection of avian embryonic erythrocytes: Analysis of a system for studying developmental gene expression. J. Cell. Biol. 105: 1055-1065.

Maniatis, T., E.F. Fritsch, and J. Sambrook. 1982. Molecular cloning: A laboratory manual. Cold Spring Harbor Laboratory, Cold Spring Harbor, New York.

Mantovani, R., N. Malgarette, S. Nicolis, B. Giglioni, P. Comi, N. Cappellini, M. Tiziana Bertero, F. Caligaris-Cappio, and S. Ottolenghi. 1988. An erythroid specific nuclear factor binding to the proximal CACCC box of the $\beta$-globin gene promoter. Nucleic Acids Res. 16: 4299-4313.

Maxam, A.M. and W. Gilbert. 1980. Sequencing end-labeled DNA with base-specific cleavages. Methods Enzymol. 65: 499-560.

McGhee, J.D., W.T. Wood, M. Dolan, J.D. Engel, and G. Felsenfeld. 1981. A 200 base pair region at the $5^{\prime}$ end of the chicken adult $\beta$-globin gene is accessible to nuclease digestion. Cell 27: 45-55.

Myers, R.M., K. Tilly, and T. Maniatis. 1986. Fine structure genetic analysis of the $\beta$-globin promoter. Science 232: 613618.

Nickol, J.M. and G. Felsenfeld. 1988. Bidirectional control of the chicken $\beta$ - and $\epsilon$-globin genes by a shared enhancer. Proc. Nat1. Acad. Sci. 85: 2548-2552.

Nomiyama, H., C. Fromental, J.H. Xiao, and P. Chambon. 1987. 
Cell-specific activity of the constituent elements of the simian virus 40 enhancer. Proc. Natl. Acad. Sci. 84: 78817885.

Plumb, M.A., V.V. Lobanenkov, R.H. Nicolas, C.A. Wright, S. Zavou, and G.H. Goodwin. 1986. Characterization of chicken erythroid nuclear proteins which bind to the nuclease hypersensitive regions upstream of the $\beta^{\mathrm{A}}$ and $\beta^{\mathrm{H}_{-}}$ globin genes. Nucleic Acids Res. 19: 7675-7693.

Rosenfeld, P.J. and T.J. Kelly. 1986. Purification of NF-1 by DNA recognition site affinity chromatography. $I$. Biol. Chem. 261: 1398-1408.

Rupp, R.A.W., R.H. Nicolas, U. Borgmeyer, V.V. Lobanenkov, M.A. Plumb, A.E. Sippel, and G.H. Goodwin. 1988. TGGCA protein is present in erythroid nuclei and binds within the nuclease-hypersensitive sites $5^{\prime}$ of the chicken $\beta^{\mathrm{H}_{\text {- }}}$ and $\beta^{\mathrm{A}_{-}}$ globin genes. Eur. J. Biochem. 177: 505-511.

Shüle, R., M. Muller, H. Otsuka-Murakami, and R. Renkawitz. 1988. Cooperativity of the glucocorticoid receptor and the CACCC-box binding factor. Nature 332: 87-90.

Stevens, P.W., J.B. Dodgson, and J.D. Engel. 1987. Structure and expression of the chicken ferritin-H subunit gene. Mol. Cell. Biol. 7: 1751-1758.

Superti-Furga, G., A. Barberis, G. Schaffner, and M. Busslinger. 1988. The -117 mutation in Greek HPFH affects the binding of three nuclear factors to the CCAAT region of the $\gamma$-globin gene. $E M B O$ I. 7: 3099-3107.

Xiao, J.-H., I. Davidson, M. Macchi, R. Rosales, M. Vigneron, A. Staub, and P. Chambon. 1987. In vitro binding of several cell-specific and ubiquitous nuclear proteins to the GT-I motif of the SV40 enhancer. Genes Dev. 1: 794-807. 


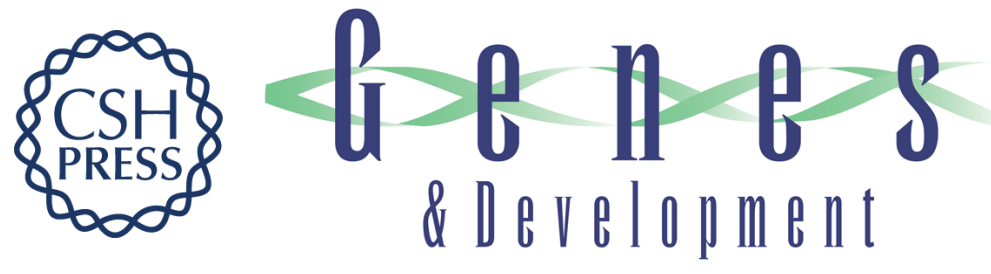

\section{Developmental modulation of protein binding to beta-globin gene regulatory sites within chicken erythrocyte nuclei.}

P D Jackson, T Evans, J M Nickol, et al.

Genes Dev. 1989, 3:

Access the most recent version at doi:10.1101/gad.3.12a.1860

References This article cites 41 articles, 18 of which can be accessed free at:

http://genesdev.cshlp.org/content/3/12a/1860.full.html\#ref-list-1

License

Email Alerting

Service

Receive free email alerts when new articles cite this article - sign up in the box at the top right corner of the article or click here.

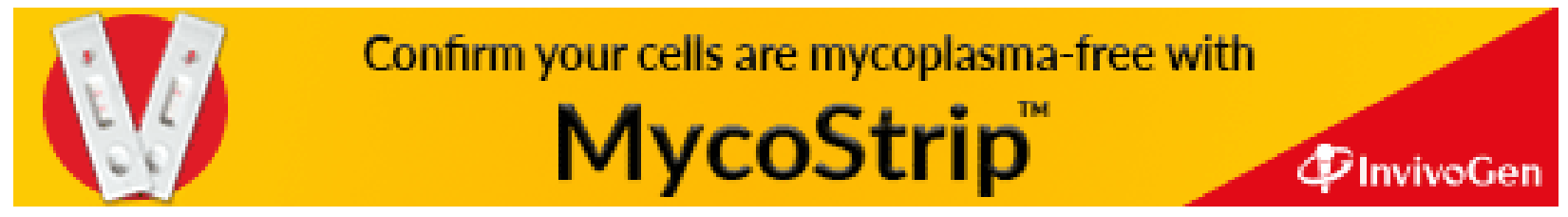

